\title{
Caught in Circular Time: Spatiotemporal Narrative Concerns in Cloum McCann's Let the Great World Spin (2009)
}

Fadwa Kamal AbdelRahman

Professor, Faculty of Al-Alsun (Languages), Ain Shams University, Egypt.

\begin{abstract}
Is History moving forward in a progressive manner, or is it circular, repeating itself in an endless cycle of violence and counterviolence?

Colum McCann's novel, Let the Great World Spin, seems to raise this question as it tries to deal with the $9 / 11^{\text {th }}$ trauma by referring back to the Vietnam War.
\end{abstract}

Through an earlier incident that also involves the now famous Twin Towers of the World Trade Center, McCann aspires to dissect the different layers of life in New York. Though the text has been called a novel about New York by many critics, a closer look at the novel reveals that temporal concerns are intertwined with spatial ones to create a very intricate narrative. It thus helps the reader expand his experience of the present to include the past and the future in one circular totality that deems the livable space open for a (re)negotiation of suffering and pain in such traumatic times. 


\section{Caught in Circular Time: Spatiotemporal Narrative Concerns in Cloum McCann's Let the Great World Spin (2009)}

\section{Fadwa Kamal AbdelRahman}

This life as you now live it and have lived it, you will have to live once more and innumerable times more; and there will be nothing new in it, but every pain and every joy and every thought and sigh and everything unutterably small or great in your life will have to return to you ... The eternal hourglass of existence is turned upside down again and again, and you with it, speck of dust.

(Nietzsche, The Gay Science, book IV, s. 341)

Once Upon a time and long ago, in fact so long ago that I couldn't have been there, and if I had been there, I couldn't be here, but I am here, and I wasn't there, but I'll tell you anyway: Once upon a time and long ago.... (McCann, Let the Great World Spin 68)

$9 / 11^{\text {th }}$ is a real "semiotic event, involving the total breakdown of all meaning-making systems" (Versluys 8). It has literally shaken the American society, which woke up to the ugly realities of global terrorism hitting home. It has resulted in a "rupture" that marks a real and tangible change both in the American society and the world at large. Its huge impact transcends the direct losses to take on a rather symbolic significance as terrorism surpasses the present moment and acquires a circular character turning into an "echo from the past and a transitional moment which lays the grounds for the future, becoming (again) the origin for another moment in the future and so on" (Borges 5). Though Literature, in general, and fiction in particular, couldn't have remained mute in relation to such a major event, the resulting works were not up to its enormity and complexity. R.B. London sums up the causes of this deficiency in a number of points that range between the overpowering nature of the event as well as the crises it creates, and that "it's too soon" to write analytically about such a huge event ("After the Unthinkable").

Most of the criticism dealing with 9/11 fiction, fails to include Colum McCann's novel, Let the Great World Spin (2009) in its scope. However, the novel has been a great popular and critical success that won its author the US 2009 National Book Award and the 2011 International IMPAC Dublin Literary Award, one of the most lucrative literary awards in the world. This paper sets out to analyze how this novel manages to evade sacrificing the fictional and technical elements in favour of the hugeness of the event and to attain such a balanced representation that puts it under the category of great fiction. This necessarily includes an examination of the text's structure, its use of time and space, multiprespectivity and intertextuality. The paper will depend extensively for its theoretical framework on Peter Brooks' Reading for the Plot: Design and Intention in Narrative, relying on its critical practice and analysis of narrative plotting. McCann 
has managed to write a novel about $9 / 11$, but without being limited to its direct discourse, without being implicated in its after-shock. He has succeeded in dealing with the life-changing event without depreciating it or falling into a melodramatic and sentimental representation of its repercussions. To achieve this, he resorts to fragmenting it into "metaphors and comparisons, serving to sublimate individual and private affairs and adventures" (Bakhtin 217). Through such metaphors "the past [gains] the capacity to imagine us, and we it" (Ozick 62). Furthermore, if according to the Nietzschean schema "every pain and every joy and every thought and sigh and everything unutterably small or great in your life" (Nietzsche, Gay Science book IV, s. 341) is nothing but a repetition of a previous one, then it makes perfect sense to deal with this tragedy by tackling the last one, the last war, the Vietnam war which took place a generation before (1955-75, but the peak of American interference was at the time of Nixon 1969-74).

The novel is conveniently set in 1974, not only because it is towards the end of the war that the real amount of the American losses is known, and its real impact is appreciated, but also as this helps create constellations where repercussions of a multiplicity of histories can be woven together. Thus, by making use of the provision of literature that "allows us to become ourselves by becoming somebody else" (McCann, "What Ulysses Did"), McCann manages to reimagine the nature of the present by dealing with "eternal recurring facts," with war, with loss and pain, but also with redemption, compassion and endurance; with trying to find solace in times of crisis. Hence,
Vietnam "was as good a place to start as any" (Let the Great World Spin 86). ${ }^{1}$

The idea of eternal repetition might seem frightful, but like all the other terrifying "realizations" in Nietzsche, the superman, is the one who represents "the ideal of the most high-spirited, vital, world-affirming individual, who has learned not just to accept and go along with what was and what is, but who wants it again just as it was and is through all eternity, insatiably shouting da capo [from the beginning]" (Nietzsche, Beyond 5051). So accepting the tragic facts of life and being at peace with the idea of their recurrence is the way of the strong. According to Nietzsche, history seems to take a circular route, repeating itself in an endless cycle of wrong decisions that are almost uncanny in their similarity, in the repetition of the same mistakes, in beginning with the same premises, expecting each time things to end up differently. In this sense, the idea that history moves forward and people (collectively) learn from their past mistakes becomes a myth. But hope resides rather in the ability of people in the past to manage and live through all kinds of misfortunes like a Phoenix regenerating itself from its ashes over and over again.

On a more textual level, Peter Brooks asserts that the structure of the novel, as a genre, depends heavily on repetition. Not only is the urge to repeat one symptom of trauma in the case of tragic events, but it also gives the semblance of control, of mastery. ${ }^{2}$ In this sense, the novel not only becomes a "total metaphor" of another war, but it is also metonymic of a nation's strength and its ability to get over its hardships. In this sense, the Twin-Towers of the World Trade Centre become the meeting-up of multiple stories past and 
present. McCann recourses to one of the memorable moments in the history of the place when a French high-wire artist, called Philippe Petit, performed an unauthorized walk between the towers on the $4^{\text {th }}$ of August 1974. The only image included in the novel is a picture of Petit on the string, and at the upper left corner we see a plane as if heading towards one of the towers, ready to hit it. This synchronicity, or "meaningful coincidence," not only works as a foreshadowing of the future event in 2001, but also becomes a trope that helps link the multiple times of the narrative and enhance the dynamic engagement of the reader with the plot. The towers become "the collision point of stories" and the walk turns up to be "one small scrap of history meeting a larger one. As if the walking man were somehow anticipating what would come later" (LGWS 325). It is here that "time takes on flesh and becomes visible for human contemplation, [and] space becomes charged and responsive to the movement of time and history and the enduring character of a people" (Bakhtin 84). Thus, this becomes ultimately "a book about the 70s - 'Flared jeans, shaggy hair, disco lights, that sort of thing' ... [However, it is also] about NOW but in the guise of long ago," McCann explains ("Let the Great World Spin Q\&A").

On the other hand, Petit's walk might seem at first glance to be representative of aesthetic mastery, triumph over the limitations of the human body and of geographical restrictions: "for it all was beauty. Walking was a divine delight. Everything was rewritten when he was up in the air. New things were possible with the human form. It went beyond equilibrium" (LGWS 164). However, the similarities between the walk and the suicide attacks of $9 / 11^{\text {th }}$ cannot be overlooked. The similarity resides in the craziness of the endeavor and the sheer cheapness of the involved human life: "So flagrant with his body. Making it cheap. The puppetry of it all. His little Charlie Chaplin walk, coming in like a hack on her morning. How dare he do that with his own body? Throwing his life in everyone's face?" (113). When we close-read the words uttered by Claire in the above description of the scene of the walk: "flagrant", "puppetry", "throwing his life", we can arrive at the negative connotations that bring to mind the similarities to the latter incident.

The complexity and multiplicity of all the thematic concerns of the novel are voiced through an equally complex and versatile unicursal structure. In his interviews, McCann is fond of referring to John Berger's assertion that "never again will a single story be told as if it were the only one" (McCann, "Elsewheres" 107; "Great Instincts"). In line with this assertion, comes the circular structure of the novel, which permits a refraction of meaning by resorting to different types of repetition that denote different facets, multiple layers, various meanings of what is basically the same. Peter Brooks asserts that "[n]arrative ... must ever present itself as a repetition of events that have already happened.... An event gains meaning by its repetition, which is both the recall of an earlier moment and a variation of it. The concept of repetition hovers ambiguously between the idea of reproduction and that of change" (Brooks 99-100). Those repetitions "take us back in the text, ... [to] allow the ear, the eye, the mind to make connections, conscious or unconscious, between different textual moments, to see past and present as related 
and as establishing a future that will be noticeable as some variation in the pattern" (Brooks 99).Consequently, the narrative "does not move in a straight line but rather in the rhythm of systole and diastole. Hence, like a chest expanding to inhale" (Kern 24). Through a circular form-"Circles of circles" (LGWS 52-53), the novel takes as its focal point the tightrope walker and all the other characters and events seem to revolve round him. Set in one day from morning till night (with many flashbacks and time shifts going on), everything and every character seems connected one way or another to every other character and to the walker "... and when you go around in circles, brother, the world is very big, but if you plow straight ahead it's small enough" (53).

According to Peter Brooks, narrative desire is intrinsically a "desire for the end" (Brooks 52), but in order to combat the death-drive and the need for closure, the text has to linger in the middle by suspending time and caring less for its progression than with the "recognition or anagnorisis which, said Aristotle, every good plot should bring" (Brooks 92). The world, like Adelita's bedroom, "seem[s] stretchy" (LGWS 278). You "can look from one room to the other and the curved glass makes it either narrow or wide. Depending on what side you happen to be." Lingering in the middle, through repetition, leads to the fusion of meanings and indicators that is the ultimate aim of the text where "the present, the now, winds around itself, and nothing is tangled. The river is not where it begins or ends, but right in the middle point, anchored by what has happened and what is to arrive" (279). Hence, "systems of repetitions," like those used by McCann "[confound] the movement forward to the end with a movement back to origins, reversing meaning within forward-moving time, serving to formalize the system of textual energies, offering the pleasurable possibility (or illusion) of "meaning" wrested from "life" (Brooks 108).

Those repetitions can be both "returns to and returns of" textual material. "A return to" is exemplified in the centrality of the walker's performance to which all the other events and characters return for reference and impact. For example, Claire, Gloria and the rest of the support group of grieving mothers meet on that day in Claire's home in Park Avenue. Their meeting routine is disrupted and Claire is so upset because the tight-rope walker steals the attention of the group, and she is unable to tell the story of her son Joshua or to show them his souvenirs. It also happens that her husband, Solomon Soderberg is the judge who handles Petit's case in court. Corrigan was driving near Park Avenue and "had seen something he could not forget ... a man, a building" (LGWS 283). Fernando, the photographer, in his ride through the underground, is aware of an extraordinary event taking place up in the Manhattan area through the large number of policemen running here and there. He decides to interrupt his trip, even if this means he would be late for his work in the barbershop. Even Sam Peters, the kid, and the group of programmers on the West coast in the Etherwest computer laboratory in Palo Alto try to keep posted with the news of the walker in Manhattan through public payphones near the twin towers, taking "bets on whether he' $\mathrm{d}$ fall or not" (178).

In a kind of "return to the future" this time, McCann is very careful to insert technological advances that were still in their cradle at that time in the mid- 
seventies. So the programmers in Palo Alto have actually "been working six months on [a graphics program], but the Pentagon's been developing it for years. If there comes another war, they'll be using this hack, that's for sure" (LGWS 197). In addition, Joshua, Claire's son and the Harvard graduate, also used to work in Palo Alto Research Center (PARC) before being sent to Vietnam as a technical expert. Joshua develops a program to electronically count the dead soldiers, others were used to calculate the logistics and ammunition...etc. It was the time when new war techniques and technological advancements were being launched when it was apparent that "the machines would revolutionize the world" (101). It was also the time when anti-war groups and peace protestors were not only organizing demonstrations and rallies in the real world, but also resisting warfare in the virtual world by hacking "in to chew away parts of their [the army squad's] program ... trying to break into their machines" (101). All these details which are all too familiar in our post millennial world, were not that familiar in the midseventies. However, they help to bring forth the relation between the past and the present and to highlight the allegorical meaning of the text where the surface story/war is used to stand for another war on the deeper level.

As "[n]arrative always makes the implicit claim to be in a state of repetition, as a going over again of a ground already covered" (Brooks 97), one important tool to achieve the "return of the text" is multiperspectivity in its different forms. McCann uses multiple narrators and /or points of view to return to the same incidents and relate them from different perspectives. Multiple narrators are also utilized to provide fragments of the same story, or facets of the same character lending more complexity to the text and turning it to a hall of mirrors circularlly representing different reflections of the same incident/character. Let the Great World Spin comes in thirteen chapters, apart from the first chapter narrated by a $3^{\text {rd }}$ person omniscient narrator, each of the remaining twelve chapters is either narrated by a $1^{\text {st }}$ person narrator or a $3^{\text {rd }}$ person perspective aligned to a focalizer from amongst the characters of the novel. For example, there is a "return of the text" to the accident that results in Corrigan's and Jazzlyn's deaths. The accident and the ensuing attempts to rescue Corrigan at the hospital are narrated three different times, both repeating the same details from the perspectives of Ciaran in chapter two, Lara in chapter three and finally Adelita in chapter eleven and complementing one another with extra details that could not have logically been provided by the other characters as first person narrators.

Ciaran reports what he has heard about the accident and how it happened, then as a first hand witness of the time at the hospital; Lara narrates the accident as it takes place on the road in Manhattan; Adelita recounts Corrigan's last moments at the hospital when she arrives there. What is noteworthy is that all three narrators are represented as unreliable. This unreliability is confirmed through similar stylistic devices found in the three versions of the incident. Ciaran repeats the phrase "may be" many times while trying to narrate the accident: "maybe he hit the indicator, maybe he didn't, maybe he was dizzy or tired or out of sorts, maybe he'd gotten some medicine that slowed him or fogged his vision, maybe he tapped the brake, maybe he cut it too hard, maybe he 
was gently humming a bit of a tune, who knows" (LGWS 69). The same happens with Lara who says: "the driver must have had his foot on the brake, or his rear lights weren't working, or maybe he had been riding the brake all along" (115). Her narrative reliability is also undermined by the fact that " $[t]$ here was so much cocaine still pumping through our [Lara and Blaine's] bodies even at that hour" (116). This unreliability deprives the reader of a secure source on which s/he can rely in his/her assessment of the events and characters and make him/her more open for the recursive nature of the text.

In the same vein, Adelita tries to figure out Corrigan's last words and their meaning but she too is unable to reach the truth. She ultimately says: "perhaps he woke up, stumbled out of his van in the early morning, and saw the man up there, challenging God, ... who knows, I cannot tell. Or maybe it was the court case, that the walker got off free, while Tillie was sent away for eight months, maybe that annoyed him... maybe he thought she deserved another chance .... Or maybe something else got to him" (LGWS 284). The scene juxtaposes their happiest moments, when Corrigan finally gets over his inner conflict between his vows to his God and his love for Adelita and his last moments at the hospital when Adelita finally arrives and is at his deathbed. The circular way their relation is represented is meant to bring home the transient nature of time, which becomes visible for human contemplation: "[t]his is the future as we see it. The swerve and the static. The confidence and the doubt" (281). Through the narrative, the reader shares Adelita's desire to freeze time in order to have him "remain here-exactly here-on the couch, without moving" (283), but also to understand the impossibility of it all. This circularity further emphasizes the Manichean nature of the basic truths of human existence: of life and death, happiness and grief, fulfillment and loss, underlying the fundamental "problem of temporality: man's time-boundedness, his consciousness of existence within the limits of mortality" (Brooks XI).

Another type of multiperspectivity is presented through the court scene. This is first represented by Ciaran as a first person narrator. He relates the extent of Corrigan's anxiety on behalf of the hookers starting from the time of their arrest. The way Corrigan stands up to the police and "storm[s] towards the last remaining cop car, brandishing Jazz's key chain ... [and asks:] Who's going to look after her kids? Are you going to leave them there on the street?" (LGWS 62-63) gives a glimpse of the ingenuity of his care for others. Corrigan then goes to court which he ironically calls " $t]$ he parthenon of justice", but then asserts that "they call it the Tombs" (LGWS 64). In a return of the text to the court scene in chapter ten, we get it from Judge Soderberg's point of view. The latter scene complements the picture for the reader as it includes details from the trial, not included in the former. The circularity of the narrative is nonetheless confirmed through the negative description of the court towards the end of the text as "a shithouse" (253). Thus it is a "tomb" for the defendants and a "shithouse," whose filth cannot be evaded, for the members of the legal system. Soderberg is so blind to the actualities of the hooker's life to the extent of mistaking Corrigan for a pimp: "a strange-looking pimp. Not the usual type. No matter. They came in all sizes and packages. Truth was, the women were 
victims of the men, always were, always will. At the essential core, it was idiots like the pimp who should have been jailed" (269-70). This misconception doubled by the way Soderberg is so anxious to be done with the Henderson case in order to "pull out a good performance for the tightrope walker" (272), casts a deep shadow on the legal system in New York and its failings.

This is not the only time Corrigan falls victim to a false reading of character. Adelita, on first seeing him with the "cuts and bruises on his face ... [figured out that] he looked ... like exactly the sort of man I should stay away from" (LGWS 277). His own brother seeing the splotchy bruises on his arm, hastily arrives to the conclusion that he is "scoring heroin" (42). It is only later on that Ciaran confronts him with his suspicion and learns of his illness. It is rather significant that Corrigan is never given voice in the first person despite the fact that his story is one of the central and shaping ones in the novel; it is the "story of stories" (44). He is always represented indirectly through the lenses of another character. The reader first gets to see him through the eyes of his brother Ciaran. Corrigan's faith, his self-denying kind of life is never idealized nor sentimentalized. Ciaran narrates his type of religious commitment with contempt: "he was a fool-all his religiosity, all his pious horseshit, it came down to nothing, the world is vicious and that's what it amounts to, and hope is nothing more or less than what you can see with your own bare eyes" (39). His many acts of kindness are always undermined by the kind of humiliation he gets, whether from the hookers he opens his heart and apartment to, or their pimps who beat him up fiercely many times, or even the children on the street who make him their laughing stock. However, Ciaran is eventually able, under the influence of his brother whom he raises doubt about, to empathize with the hookers and to see the human essence beneath their miserable existence or as Corrigan says: "they're good people ... They just don't know what it is they're doing. Or what's being done to them. It's about fear. You know? They're all throbbing with fear. We all are" (29). Ciaran recognizes that "it seemed ... that Corrigan was right, that there is something here, something to be recognized and rescued, some joy" (46). This affirmation is highly important in a text that tries to deal with human terrors, doubts and the need to combat "this fear, covering our faces and tongues. If we stopped to take account of it, we'd just fall into despair. But we can't stop. We've got to keep going" (30).

It is also noteworthy that the "return of the text" in its many instances and the nature of the narrative and language used therein are very much in line with the postmodern nature of the text which denies the reader any secure centre of truth and meaning. Not giving voice to Corrigan, the Christ-like character, and enveloping him in a haze of doubt and ridicule, is one way through which the text refrains from clearcut conclusions. The ultimate meaning of the text is left for the reader to deduce from the fragmented narratives and the individual dilemmas the characters have to go through and overcome. This challenges the reader into deconstructing and reconstructing the kind of reality given by the outside world.

As part of the repetitive structure, the text ultimately ends up revisiting the whereabouts of its early chapters. Apart from the first prologue-like chapter, the 
first chapter of book one under the title "All Respects to Heaven. I Like it Here" is narrated by Ciaran in the 1st person mode. It introduces the main characters in the Bronx: Corrigan, Tillie and Jazzlyn, and sets the tone of the whole book. The narrative moves from the brothers' life in Ireland, to Ciaran's arrival in New York and his early experiences in the Bronx, to the final death of Corrigan and Jazzlyn in Mahatten. The last chapter of the novel under the title "Roaring Seaward. And I Go" (which is a quote from the last line of "Locksley Hall" as will be clarified later) is set thirty two years later. In this chapter the text comes full circle. It is narrated from a $3^{\text {rd }}$ person perspective with Jaslyn as a focalizer. It begins with a description of the photo of the tightrope walker on the same day Jazzlyn dies, thus establishing the link between the present and the past, pointing out the circularity of time and of the narrative representing it. The latter chapter re-visits all the places of the former, moving with Jaslyn from the airport to Park Avenue, Manhattan, to the Bronx and through time shifts to Ireland.

It represents through flashbacks the long-lasting relationship between Gloria and Claire, which traverses all racial, economic and cultural barriers, the possibility of moving beyond the discourse of hatred and segregation to a more inclusive culture capable of uniting all kinds of people. Acts of empathy and love bring together people that otherwise seem to belong to different worlds and help them get over their personal tragedies. Gloria, having lost her three sons in the Vietnam War, finds solace in raising the two orphaned girls, Jaslyn and Janice, who are left alone in the world after the death of their mother and grandmother. Claire also finds support through her unlikely friendship with Gloria and her taking part in raising the girls. The image of Gloria and Claire together becomes emblematic of peace and coexistence. They are described sitting "on wooden chairs in the back garden, by the plastic pool, near the red fence [,looking] so different, Claire in her neat skirt, Gloria in her flowered dress, as if they too were running on different levels of the pavement, but in the same body, the two of them combined" (LGWS 330).

In the same token, the representation of present-day Dublin, through Jaslyn's visit to meet "Corrigan's brother" (LGWS 341) is another circular leap that helps drive home the final message of the novel. Thirty two years ago, Dublin was a city that "had no desire to get out from under its grayness" (16). Ciaran decides to leave, heading to America after surviving an explosion related to the ongoing civil war. But Dublin has learnt its lesson and decided at one point of its history to shed off all that violence and arrive at a formula for coexistence. Irish people have managed to grow out of the vicious circle of violence and counter-violence consequently turning Dublin into "a boomtown" (341). This change is also embodied in Ciaran who turns from being a lost late hour hippie, working as a barman in the Bronx, to a very successful man, the "CEO of an internet company in the high glass towers along the Liffey" with another office in Silicon Valley (341).

On another note, Brooks draws attention to the parallelism between the structural function of narrative closure and the death drive as he points out that "[a]ll narrative may be in essence obituary in that ... the retrospective knowledge that it seeks, the knowledge that comes after, stands on the 
far side of the end, in human terms on the far side of death" (95). The last chapter witnesses the death of the older generation, of Gloria and Claire. Surrounded by her loved ones, by the girls and Claire, playing, laughing and singing, "Gloria left with a smile on her face. ...If there was any way to go, it was a good way to go" (LGWS 339). The epiphany Gloria has before her death attests to the everlasting truth of life: "[t]he only thing worth grieving over, she said, was that sometimes there was more beauty in this life than the world could bear" (339).

Claire has a stroke and is bed-ridden; her relatives cannot tolerate her African American "niece," Jaslyn, who feels unwelcomed in Claire's home for the first time in her life. This attitude, in addition to the previous discrimination against Jaslyn in the hotel, where the receptionist asks for her I.D. "though the couple in front of her were not asked for theirs" (LGWS 340), makes it clear that America is not yet over its racially discriminatory culture. Jaslyn is tired "of the people who tell her that she's not a normal AfricanAmerican, as if there were only one big normal box that everyone had to pop out of, the Swedish, the Poles, the Mexicans..." (327). The nation is still entangled in the "slick hysteria of war" (347), in a circular infinity through a time "not too distant from the present time, yet a time not too distant from the past, the unaccountable unfolding of consequence into tomorrow's time" (349). Thirty-two years later, the people haven't learnt their lesson and the uncanny similarities embodied in the circular repetition of things, leave little hope for salvation.

Sheila Hones rightly observes that " $[\mathrm{t}] \mathrm{he}$ reader's encounter with fiction involves multiple spatial dimensions mixed together: not just places visited and maps used but also books read, stories overheard, and many more" (102). In those encounters, readers witness "texts spinning out of texts-[and this] is used by McCann throughout The Great World in such a way as to juxtapose otherwise unconnected times and places and to highlight the ways in which the world of the imagination, of reading and writing, intersects or intrudes into the material world of daily life" (Hones 126). In addition, intertextuality itself is by default a kind of repetition, or as a researcher once called it "infectious echoes from the past" (Cairney 478). Brooks asserts that those repetitions result in "a binding of textual energies that allows them to be mastered by putting them into serviceable form, usable 'bundles' within the energetic economy of the narrative" (100). Or as McCann himself remarks in a 2008 speech: "The best literature is connected," and we "are word-linked. What gives off the deepest sparks is the democracy of story-telling" ("Things Come Together"). Many studies have highlighted the intertextual references in Let the Great World Spin. The most extensive of those is Hones' study which establishes the link between McCann's novel and many intertexts, fictional and nonfictional. From Petit's memoir, To Reach the Clouds (2002), to F. Scott Fitzgerald's The Great Gatsby (1925), as well as from Tennyson and Larkin to Whitman, and Rumi. However, those studies mainly deal with the novel and its intertextual references in a purely American, and more particularly New York context. Such studies do not pay due attention to the subtext of otherness that the novel is written in relation to. The novel as it relates to both the Vietnam War and the War on Terror that follows the 9/11 attacks, has the relation of America to 
the outside world, to all its "others" embedded in it. If the novel is mainly about solace, redemption and healing, McCann makes it clear that these cannot be attained through a rhetoric of xenophobia and exclusion.

In an interview, McCann said: "[t]he whole time I was writing this novel, there was only one other novel I wanted to write, and that was about a woman in a market in Baghdad, that would be only novel [sic] that could have twisted my heart backwards in the same way" ("Elswheres" 104). Against the tide of Islamophobia that followed $9 / 11^{\text {th }}$, McCann stands out with his Irish background that made him aware of those "horrible years of colonial oppression" (105). Having lived within a community dominated by oppression, violence and counter-violence, he understood that hatred won't lead anywhere: "I saw what the bombings could do. And I lived long enough to know that peace could come out of it" (104). He understood what Benjamin R. Barber means when he confirms that "no American child may feel safe in its bed if in Karachi or Baghdad children don't feel safe in theirs" (qtd in Bauman 26). Joseph Lennon, McCann's interviewer, accurately describes his fiction as "a tool for developing empathy" ("Elsewheres" 104). McCann believes that "[t]he job of fiction is to get at the texture and the truth and the deep honesty of what it's like to live inside your own - and other people's-skin" (102). Readers are induced to wonder with McCann, if this function of fiction "isn't about empathy, then I don't know what it's about" (104).

McCann is keen on demonstrating through his text that just as "the city was bigger than its buildings, bigger than its inhabitants too...[,] [i]t accepted whatever came its way, the crime and the violence and the little shocks of good that crawled out from underneath the everyday" (LGWS 248). Everything "in New York is built upon another thing, nothing is entirely by itself, each thing as strange as the last, and connected" (306). This palimpsestic nature of the city extends to its global culture and how it incorporates otherness within its very tissue. Muslims are not just the detestable terrorists and suicide bombers who hate the Americans and aim at destroying their civilization, they are part and parcel of the universal human culture, a part that cannot be written off or obliterated. This palimpsest is also embodied in the "literary techniques of reading historically, intertextually, constructively, and deconstructively at the same time [that] can be woven into our understanding" of the text (Huyssen 7). In this case, every utterance becomes a kind of repetition, an echo of previous texts and sign systems, "traces and tracings of otherness, since they are shaped by the repetition and transformation of other textual structures" (Alfaro 268). Thus, intertextuality is another type of repetition taking a vertical rather than a horizontal direction. The title of the novel is an excellent proof of this premise. " 'Let the Great World Spin' comes from Alfred Tennyson's poem, Locksley Hall, which, "in turn [is] heavily influenced by the 'Mu'allaqat,' or the 'Suspended Poems,' seven long Arabic poems written in the sixth century" (Author's Note). The palimpsest nature of the title attests to the human continuity between peoples and cultures in their quest for solace and comfort in times of crisis.

Not only is the title of the novel taken from Tennyson's poem, but also a number of the chapters' titles are direct quotations 
from it. "Locksley Hall" is a dramatic monologue narrated in the first person, recounting the experience of a soldier who comes across his childhood home while traveling with his military unit. He leaves his comrades briefly to visit a setting (Locksley Hall), which prompts intense memories, regrets, and anger; eventually, he moves on from bitterness to hope for a positive future and finally leaves Locksley Hall again to return to his unit and to carry on with his life. Thus, the intertextual references, the echoes from Tennyson are used to imply the main themes of the novel: all the negative feelings, how to handle memories, the need to carry on, to continue on your way, the need for solace and consolation, to "[i]magine endurance" (LGWS 84). The same themes are also very clear in the older layer of the palimpsest, in the Suspended Poem of Imru al-Qays (AmriolKais), the poet says: "Thus I spoke, when my companions stopped their coursers by my side, and / said: 'Perish not through despair: only be patient"" (9).

The intertextual echoes from Jalalulddin Rumi are also outstanding as they resonate throughout the novel giving it a sufist and spiritual edge especially when they come from the most unlikely quarters, from Tillie, the hooker, who recites lines from Rumi all the time. Coleman Barks, the translator of Rumi's works into English describes his poetry as "the mystery of opening the heart" (Ali). Though the most carnal character in the novel, she is also the most poetic. The memory of her week of poetry at the Sherry-Netherlands hotel is a heavenly one. She insists that "if I was given one week to live, just one week again, ... that week at the SherryNetherlands is the one I'd repeat" (LGWS 209). Apart from money, the middleEastern man gives her two things her world denied her: respect and poetry. She confirms that "nothing made me feel better than him just looking at me, appreciating what he saw. That's what good men dothey appreciate" (213). She spends the whole week reading poetry and "feeling in heaven and floating on a cloud" (209). He told her about "the desert in Syria and how the lemon trees look like little explosions of color" (213); she told him the story of the old couple taking a walk in Central Park to, their love defying the danger" (214). This professor of Persian, represents through his gentle literary soul everything that is opposite to the aggressive sentiments governing the public's attitude towards the other. The many times Tillie recalls her memories with him refer to a "return of the text," providing extra details and more insight into her character.

Furthermore, Rumi opens a world of beauty to her, she "never read nothing like that before. Made me want to have a fig tree" (209). The fig tree itself has a palimpsest nature as it has acquired a symbolic significance throughout ages beginning from the story of creation, with Adam and Eve using its leaves to sew clothes to cover their naked bodies, to Krishna and Buddha, to the three Abrahamic religions: Judaism, Christianity and Islam. ${ }^{3}$ Through the special status it has acquired for all those different peoples and cultures, the tree becomes emblematic not only of spirituality but also of multiplicity. Rumi himself, born in $13^{\text {th }}$ century in present day Afghanistan, later on moved to Damascus where he continued his theological education, then he settled in the city of Konya (in present day Turkey) where he was exposed to many influences from "Sufis, Muslim literalists and theologians, Christians, and Jews, as well as the local Sunni Seljuk 
rulers" (Ali). Rumi's universalism and his creed of love opened new windows for light in Tillie's heart and she discovered that 'it's no less love if you're a hooker, it's no less love at all" (LGWS 213). She "began to read Rumi all the time. I liked it because he had all the details" (214). During the bleakest moments of her life, Rumi comes handy to better express her pain. During Jazzlyn's funeral, she recites from Rumi, probably the lines that say: "But all these beams of light return to one; If you remove the walls that block the sun (Masnavi 4:415-18). Lara recounts how Tillie "began quoting some poet ... a line about open doors and a single beam of sunlight. ... Her Bronx accent threw the poem round until it seemed to fall at her feet....then she said that Corrigan was full of open doors, and he and Jazzlyn would have a heck of a time of it wherever they happened to be; every single door would be open" (LGWS 148). In prison, she tries to get a book of Rumi but the prison librarians have never heard of him. It's not until Lara comes and gives her a couple of books by Rumi that she manages to go back to her old reading habit.

The other Arab poet Tillie refers to in the passing, not in a profound way like Rumi, is "Khalil Gibran" (LGWS 62). Seeing how impressed Ciaran is by her quotes from Rumi, she offers to recite some more from Gibran. Gibran is another emblem of multiplicity. He is a Lebanese American poet who writes in both Arabic and English. His work pronounces the wisdom of the orient and gathers the Maronite Christianity of his ancestors along with the Islamic culture of his surroundings, especially in its sufist version. He adopts the view of the fundamental unity of all religions and his highly spiritual and inspirational works specially The Prophet (1923) established his reputation and made him the third bestselling poet of all time, preceded only by William Shakespeare and Lao-tzu (Acocella). Hence the intertextual echoes of Rumi and Gibran, not only contribute to the repetitious structure of the novel, but also become part of the novel's transcendence beyond hatred, beyond stereotyping, beyond totalization.

To Conclude, through a novel that depends on a multiplicity of voices, narrators, points of view, echoes from other cultures and other texts as well as repetitions (returns to and returns of textual material), McCann tries to find solace and overcome pain. McCann's text stands in a unique position endowed by his insider/outsider status which drives him to identify himself with the city he has lived in since 1986, confirming that "I'm ... a New Yorker," but in the same sentence e proceeds to say: "I'm not an American writer, certainly not" ("Elswheres" 3). This uniqueness enables him to transcend the shock and awe of the tragedy of $9 / 11$ and look deeper into its causes and effects and into those that underlie all similar tragedies, past and present. The morale of the text suggests that the only way out of this vicious circle that entraps time in its repetitious rhythm, to find consolation especially in times of crisis is through inclusion rather than exclusion and xenophobia. The final epiphany Jaslyn has at Claire's bedside is that during our transient life on earth, "[w]e stumble on... bring a little noise into the silence, find in others the ongoing of ourselves. It is almost enough. ...The world spins. We stumble on. It is enough" (LGWS 349). The planet will never cease to spin in its circular orbit. In our short time on it, we should deal with its landmark events as 
differential and historical markers that stand witness to the continuity and heterogeneity of life and its repetitive nature. Redemption is only possible through empathy, through celebrating what brings us together as humans in an infinite tale of suffering and redemption.

\section{Notes}

1 All subsequent reference to the novel in the in-text citation will use the acronym "LGWS".

2 A number of studies dealt with Let the Great World Spin using theories of trauma by such theorists as Cathy Caruth, Michelle Balaev, Michael Roth, Roger Luckhurst, Alan Gibbs and Shoshana Felman, among others. See for example:

Cusatis, John. Understanding Colum McCann. U of South Carolina P, 2011.

Koschorreck, Maartje. "Analyzing the Network of Traumas in Colum McCann's Let the Great World Spin." COPAS-Current Objectives of Postgraduate American Studies, vol. 17, no. 1, 2016, pp. 1-21.
3 See for Example:

"When the woman saw that the tree was good for food, and that it was a delight to the eyes, and that the tree was desirable to make one wise, she took from its fruit and ate; and she gave also to her husband with her, and he ate. Then the eyes of both of them were opened, and they knew that they were naked; and they sewed fig leaves together and made themselves loin coverings." (Genesis 3:6-7); "Now Isaiah had said, 'Let them take a cake of figs and apply it to the boil, that he may recover." (Isaiah 38:21); "Then the trees said to the fig tree, 'You come, reign over us!' (Judges 9:10-11); And in the Quran: "By the fig and the olive" (The Qur'an Alteen 95:1); "It is honored since it is the holiest of all the holy trees. It can very well stand as a true symbol (satya pratika) of OM, which in turn is the true symbol of the Parabrahma Paramatman." (see http://omshantimandiram.org/Ashvattha .html). 


\section{Works Cited}

Acocella, Joan. "Prophet Motive: The Kahlil Gibran Phenomenon." The New Yorker, 7 Jan. 2008, www.newyorker.com/magazine/2008/01/07/prophet-motive. Accessed 5 May 2018.

Alfaro, Maria Jesus Martinez. "Intertextuality: Origins and Development of the Concept." Atlantis, Vol. 18, No1/2, Dec. 1996, pp. 268-285. Accessed: 15 July, 2018.

Ali, Rozina. "The Erasure of Islam from the Poetry of Rumi." The New Yorker, 5 Jan. 2017, www.newyorker.com/books/page-turner/the-erasure-of-islam-from-the-poetry-ofrumi. Accessed 5 May 2018.

Amriolkais. "The Poem of Amriolkais." Works of Sir William Jones: With the Life of the Author, Vol. X, edited by Lord Teignmouth, translated by Sir William Jones. John Stockdale, 1807, pp. 9-20.

Bakhtin, M. M. The Dialogic Imagination: Four Essays, edited by Michael Holquist, translated by Caryl Emerson and Holquist, U of Texas P, 1981.

Bauman, Zygmunt. Liquid Times: Living in an Age of Uncertainty. Polity, 2007.

Borges, Marana. "A Misunderstanding: Trauma and Terrorism in the '9/11 fiction'." TRANS 2013, doi: 10.4000/trans.702. Accessed 5 May 2018.

Brooks, Peter. Reading for the Plot: Design and Intention in Narrative. Random House, 1985.

Cairney, Trevor. "Intertextuality: Infectious Echoes from the Past." The Reading Teacher, vol. 43, no. 7, Jan. 1990, 478-84.

Fitzgerald, F. Scott. The Great Gatsby. 1925. Simon \& Schuster, 1995.

Gibran, Kahlil. The Prophet. Alfred A. Knopf, 1923.

Hone, Stella. Literary Geographies: Narrative Space in Let the Great World Spin. Palgrave Macmillan, 2014.

Huyssen, Andreas. Present Pasts: Urban Palimpsests and the Politics of Memory. Stanford UP, 2003.

Kern, Hermann. Through the Labyrinth: Designs and Meanings Over 5,000 Years. Prestel, 2000 .

London, R.B. "How 9/11 Changed Fiction: After the Unthinkable." The Economist, 2 Sept. 2011, www.economist.com/prospero/2011/09/02/after-the-unthinkable. Accessed 5 May 2018.

McCann, Colum. "Colum McCann: Great Instincts." Interview by Gabriel Packard. The Writer, 12 Oct. 2015, www.writermag.com/2015/10/12/colum-mccann-greatinstincts/. Accessed 5 May 2018. 
---."A Country of the Elsewheres." Interview by Joseph Lennon. New Hibernia Review/Iris Éireannach Nua, vol. 16, no. 2, Summer 2012, pp. 98-111. JSTOR, www.jstor.org/stable/23266708. Accessed 5 May 2018.

---. Let the Great World Spin. Bloomsbury, 2009.

---. “Let the Great World Spin Q\&A.” www.colummccann.com. Accessed 5 July 2018.

---. “Things Come Together, Things Fall Apart." Pen America, 23 June 2008, pen.org/things-come-together-things-fall-apart/. Accessed 5 May 2018.

---. "What Ulysses Did to Me." Louisiana Channel, YouTube, 9 Jan. 2014, www.youtube.com/watch?v=DcAzIzU43zE. Accessed 5 July 2018.

Nietzsche, Friedrich. Beyond Good and Evil. Translated by Judith Norman, Cambridge UP, 2002.

---. The Gay Science. 1974. Translated by Walter Kaufmann, Knopf Doubleday, 2010.

Ozick, Cynthia. "The Moral Necessity of Metaphor: Rooting History in a Figure of Speech." Harper's Magazine, May 1986, pp.62-68, harpers.org/archive/1986/05/the-moral-necessity-of-metaphor/. Accessed 5 July 2018.

Petit, Philippe. To Reach the Clouds: My High Wire Walk Between the Twin Towers. North Point Press, 2002.

Rumi, Jalal Al-Din. The Essential Rumi, New Expanded Edition. Translated by Coleman Barks and John Moyne, HaperOne, 2004.

---. The Masnavi. Book Four. Translated by Jawid Mojaddedi, Oxford World Classics, 2017.

Tennyson, Alfred. "Locksley Hall." Poetry Foundation, www.poetryfoundation.org/poems/45362/locksley-hall. Accessed 5 July 2018.

The Bible. Authorized King James Version, Oxford UP, 1998.

The Qur'an. Translated by M.A.S. Abdel Haleem, Oxford UP, 2005.

Versluys, Kristiaan. Out of the Blue: September 11 and the Novel. Columbia UP, 2009. 